\title{
A New Method for Specific Degradation of Polysaccharides
}

\author{
LEN NART KENNE, J ÖRGEN L ÖN NGREN and \\ SI GFRID SVENSSON \\ Department of Organic Chemistry, Arrhenius Laboratory, University of Stockholm, \\ S-104 05 Stockholm, Sweden
}

\begin{abstract}
A new method for the specific degradation of polysaccharides is presented. It involves the preparation of a methylated polysaccharide containing a limited number of free hydroxyl groups, at defined positions, oxidation of these to carbonyl groups by ruthenium tetraoxide and subsequent $\beta$-elimination by treatment with base. Analysis of the degraded product provides evidence concerning the sequence of sugar residues in the original polysaccharide. The utility of the method is demonstrated with two polysaccharides of known structures, the lipopolysaccharide from Salmonella typhimurium LT2 and the capsular polysaccharide from Klebsiella type 47.
\end{abstract}

$\mathbf{I}_{\mathrm{t}}^{\mathrm{t}}$

is possible to prepare methylated polysaccharides with a limited number of free hydroxyl groups, by using suitable selective procedures. Suitable methods are the acid hydrolysis of furanosidic or other acid labile linkages, sulphone degradation ${ }^{1}$ or base-catalysed elimination of pyranosidouronate residues..$^{2,3}$ Oxidation with ruthenium tetraoxide ${ }^{4}$ would then give carbonyl groups, and methoxyl or glycosyl residues in $\beta$-positions to these would be eliminated on treatment with base. A carbonyl group at the 3-position would lead to cleavage of the glycosidic linkage. Analysis of the degraded product should give information on the sequence of sugar residues in the original polysaccharide. We have recently studied the $\beta$-elimination with model substances of low-molecular weight ${ }^{5-7}$ and demonstrated that the elimination goes to completion. We now report the application of this degradation method to two bacterial polysaccharides of known structure.

\section{RESULTS AND DISCUSSION}

The O-specific side chains in the lipopolysaccharide (LPS) from Salmonella typhimurium LT2 are composed of repeating units with the structure I. The $\mathrm{D}$-glucose connected with a dotted arrow is only present in some of the repeating units. Some of the abequose residues are acetylated at C-2. This structure has been demonstrated by chemical ${ }^{8,9}$ and biosynthetic ${ }^{10}$ studies. The LPS was fully methylated by the Hakomori procedure. ${ }^{11}$ Part of the product was 
hydrolysed and the mixture of partially methylated sugars was analysed by GLC-MS ${ }^{12}$ (Table 1, column A). This analysis was in accordance with that of previous investigations. ${ }^{8}$ The methylated LPS was subjected to mild acid hydrolysis and the polysaccharide, free from lipid and components of lowmolecular weight, was recovered by gel filtration. Part of this product was methylated using trideuteriomethyl iodide, hydrolysed and analysed (Table 1, column B). Most of the 4,6-di- $O$-methyl-D-mannose now appeared as 3,4,6tri- $O$-methyl-D-mannose, with a trideuteriomethyl group at the 3-position, demonstrating that most of the abequose residues had been hydrolysed off. The only free hydroxyl groups in the recovered polysaccharide are consequently those at the 3-position of the mannose residue. The product was oxidised with ruthenium tetraoxide, thus transforming the secondary alcohol groups into keto groups.

The oxidised polysaccharide was treated with sodium ethoxide in ethanoldichloromethane and part of the product was hydrolysed and analysed (Table 1, column $\mathrm{C}$ ). This analysis indicated that the oxidation was virtually complete, as the percentage of 4,6-di- $O$-methyl-D-mannose was approximately the same as after trideuteriomethylation of the mild acid degraded polysaccharide (Table 1, column B). Another portion of the degraded material was trideuteriomethylated and hydrolysed. Analysis of this material (Table 1, column D) showed that most of the 2,3-di- $O$-methyl-L-rhamnose now appeared as 4-Otrideuteriomethyl-2,3-di- $O$-methyl-L-rhamnose. This demonstrates that, in

Table 1. Methylation analyses of the original and modified $S$. typhimurium LT2 polysaccharides.

\begin{tabular}{|c|c|c|c|c|c|}
\hline Methylated sugar ${ }^{a}$ & $T^{b}$ & A & $\mathrm{Mol}_{\mathrm{B}} \%^{\mathrm{c}}$ & $\mathrm{C}$ & D \\
\hline $2,4-\mathrm{Abe}^{d}$ & 0.32 & 8 & 1 & 1 & $<1$ \\
\hline $2,3,4 \quad C_{3}-R^{2} a^{d}$ & 0.46 & - & - & - & 32 \\
\hline $2,3-\mathrm{Rha}^{\mathrm{e}}$ & 0.98 & 20 & 22 & 34 & 2 \\
\hline $2,3,4,6-G^{e}$ & 1.00 & 14 & 17 & 20 & $3 \overline{3}$ \\
\hline $2,3,4,6$-Gal & 1.25 & 2 & 3 & 2 & 3 \\
\hline $3 \mathrm{CD}_{3}, 4,6-\mathrm{Man}$ & 1.95 & - & 23 & - & - \\
\hline $2,4,6$-Man & 2.09 & 2 & - & - & - \\
\hline $2,4,6-\mathrm{Gal}$ & 2.28 & 12 & 14 & 15 & 10 \\
\hline $3,4,6$-Gal & 2.50 & 2 & 1 & 2 & 1 \\
\hline 4,6-Man & 3.29 & $2 \overline{2}$ & 2 & 3 & $<1$ \\
\hline 2,6 -Gal & 3.62 & 15 & 15 & 21 & 17 \\
\hline $3,6-G$ & 4.30 & 1 & 1 & 1 & 1 \\
\hline $2,4-G$ & 5.10 & 3 & 1 & 2 & 1 \\
\hline
\end{tabular}

a 2,4-Abe= 2,4-di- $O$-methyl-abequose, 2,3,4 $\mathrm{CD}_{3}-\mathrm{Rha}=2,3$-di- $O$-methyl-4-mono-O-trideuteriomethyl-L-rhamnose, etc. ${ }^{b}$ Retention time of the corresponding alditol acetate relative to 1,5 -di$O$-acetyl-2,3,4,6-tetra- $O$-methyl-D-glucitol on an ECNSS-M column at $170^{\circ} .{ }^{c} \mathrm{~A}$ : original polysaccharide; B: methylated, acid degraded and trideuteriomethylated polysaccharide (see text); C: methylated, acid degraded, oxidised and alkali treated polysaccharide (see text); D: methylated, acid degraded, oxidised, alkali treated and trideuteriomethylated polysaccharide (see text). $d$ Part of this volatile ether and its corresponding alditol acetate was probably lost during the work up procedure. ${ }^{e}$ These components were separated on an OV-225 SCOT column, on which they showed $T 0.92$ and 1.00 , respectively.

Acta Chem. Scand. 27 (1973) No. 10 
the original polysaccharide, the $\mathrm{D}$-mannose residue was linked to the L-rhamnose at position 4. The stoichiometry of the latter analysis (Table 1, column D) is not very good. This may be due to non-sugar components and to losses of volatile L-rhamnose derivatives. This, however, does not affect the interpretation of the results, which are in agreement with previous results, ${ }^{10}$ obtained by other methods. The different steps in the degradation are depicted in Scheme 1. It is assumed, in this scheme, that all positions in the sugar residues are methylated unless otherwise indicated.

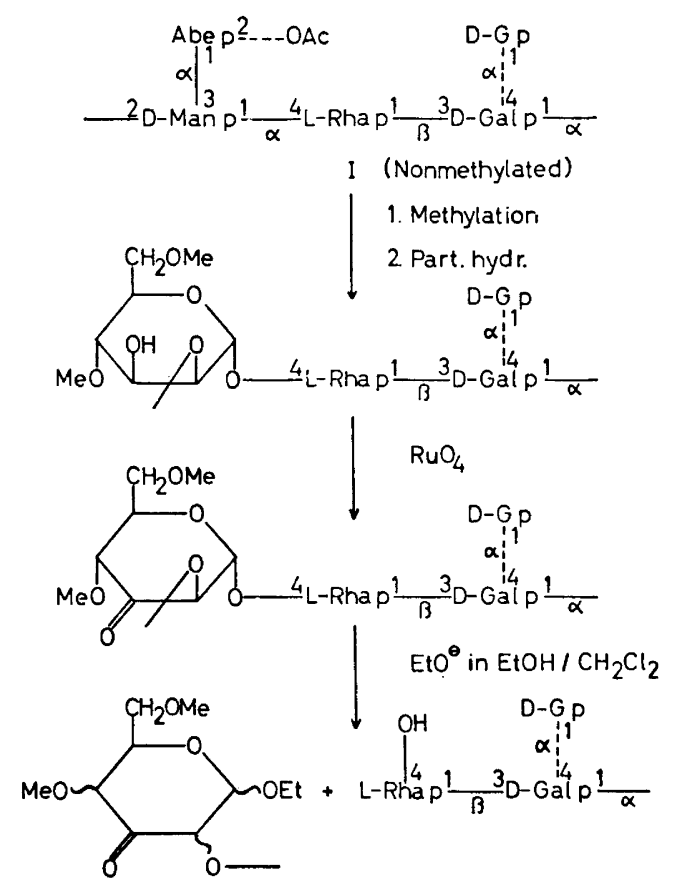

Scheme 1.

The capsular polysaccharide elaborated by Klebsiella type 47 is composed of tetrasaccharide repeating units, the structure of which (II) has recently been determined..$^{13}$ On treatment of the fully methylated polysaccharide with base followed by mild acid hydrolysis, the side chains are eliminated and a linear, methylated polysaccharide with free hydroxyls at position 3 in the $\mathrm{L}_{\text {--rhamnose residues can be recovered. }}{ }^{2}$ Methylation analysis of the original and degraded polysaccharide (Table 2, column A and B) demonstrated that the degradation was essentially complete. The degraded polysaccharide was oxidised with ruthenium tetraoxide and treated with sodium ethoxide in ethanol-dichloromethane. Part of the product was hydrolysed and analysed (Table 2, column C). The presence of some 2-O-methyl-L-rhamnose in the hydrolysate of this material indicates that some $20 \%$ of the $L_{\text {-rhamnose }}$ 
Table 2. Methylation analyses of the original and modified Klebsiella type 47 polysaccharides.

\begin{tabular}{|c|c|c|c|c|c|}
\hline Methylated sugar ${ }^{a}$ & $T^{b}$ & A & $\underset{\mathrm{B}}{\mathrm{Mol}} \%^{\mathrm{c}}$ & $\mathrm{C}$ & $\mathrm{D}$ \\
\hline 2,3,4-Rha ${ }^{d}$ & 0.46 & 19 & 3 & 4 & 1 \\
\hline $2,3 \mathrm{CD}_{3}-\mathrm{Rha}$ & 0.98 & - & 51 & - & - \\
\hline 2,3 Et-Rha & 0.92 & - & - & - & 11 \\
\hline $2,3 \mathrm{Et}, 4,6$-Gal & 1.23 & - & - & - & 77 \\
\hline 2-Rha & 1.52 & 32 & 2 & 17 & - \\
\hline $2,4,6 \cdot \mathrm{Gal}$ & 2.28 & 27 & 44 & 80 & 11 \\
\hline $2,3-G$ & 5.39 & 22 & - & - & - \\
\hline
\end{tabular}

$a$ See Table 1, note $a .^{b}$ See Table 1 , note $b .{ }^{c}$ A: original polysaccharide, carboxyl-reduced after methylation; B: methylated polysaccharide, degraded at the uronic acid residue and trideuteriomethylated (see text and Ref. 2); C: methylated, degraded, oxidised and alkali treated polysaccharide (see text); D: methylated, degraded, oxidised, alkali treated and ethylated polysaccharide (see text). ${ }^{d}$ See Table 1 , note $d$.

residues were not oxidised. On prolonged oxidation, some methoxyls were converted into formate ester groups. Another portion of the product was ethylated, hydrolysed and analysed (Table 2, column D). The presence of 3-O-ethyl-2-O-methyl-L-rhamnose, and a comparable amount of 2,4,6-tri$O$-methyl-D-galactose, supports the assumption that some $\mathrm{L}_{\mathrm{L}}$-rhamnose residues had not been oxidised. The main product, however, was 3-O-ethyl-2,4,6-tri$O$-methyl-D-galactose, demonstrating that the branching L-rhamnose residues are linked to the 3 -position of the $\mathrm{D}$-galactose residues in the original polysaccharide. The consecutive degradations depicted in Scheme 2, leaving essentially only the $\mathrm{D}$-galactose residue intact, afford chemical evidence for the presence of a repeating unit in this polysaccharide. It is assumed, in this scheme, that all positions in the sugar residues are methylated unless otherwise indicated. Similar evidence for other capsular polysaccharides has previously been obtained by biosynthetic studies ${ }^{14}$ and by hydrolysis with phage-induced enzymes. ${ }^{15,16}$

In the examples discussed above, a free hydroxyl was generated at C-3 in a sugar residue of a polysaccharide. The glycosidic linkage of that residue was then cleaved by oxidation, followed by base-catalysed elimination. Secondary alcoholic hydroxyls may, however, also be liberated in 2- or 4positions in glycopyranosides. By the same sequence of reactions, the substituent at C-4 or C-2, respectively, would be eliminated. If a methylated sugar residue is eliminated, the reducing sugar thus formed can be subjected to a second elimination, ${ }^{17}$ thus providing further structural evidence. Additional information may be obtained by degradation of unsaturated carbonyl sugar by mild acid hydrolysis with concomitant release of substituents other than those in the $\beta$-position to the carbonyl group. ${ }^{18}$

The oxidation with ruthenium tetraoxide was performed in a two-phase system, with the methylated polysaccharide in dichloromethane and ruthenium dioxide-periodate in water. ${ }^{4}$ The latter system generates ruthenium tetra-

Acta Chem. Scand. 27 (1973) No. 10 

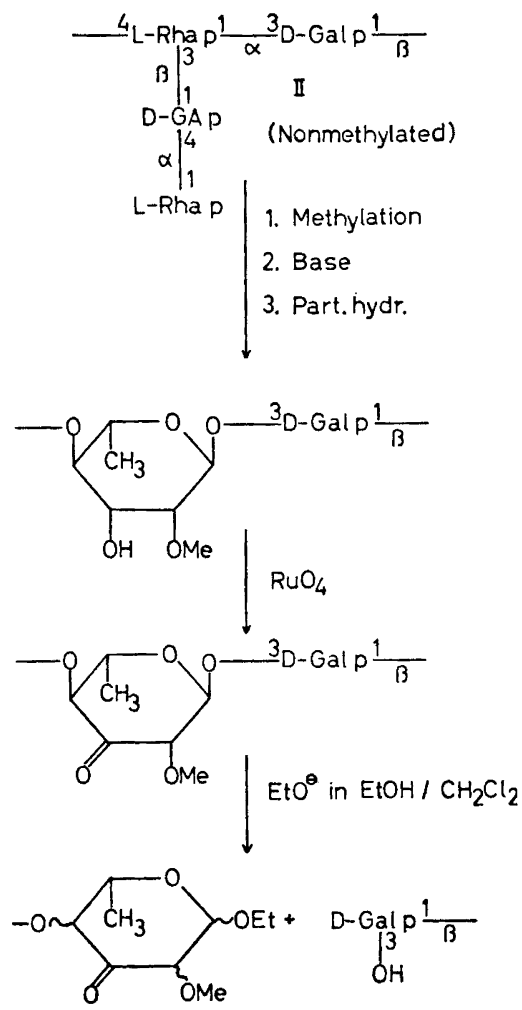

Scheme 2.

oxide, which dissolved in the organic phase. During the oxidation, black ruthenium dioxide is formed. When the rate of oxidation decreases, both phases turn yellow, as almost all ruthenium is present as ruthenium tetraoxide. Prolonged oxidation should be avoided as methoxyl groups may be oxidised into formate esters groups. ${ }^{18} \mathrm{We}$ have also found that acetylated $\beta$-glucopyranosides may be oxidised into 5 -hexosulosonates, ${ }^{19}$ as has been observed with chromic trioxide in acetic acid ${ }^{20}$ and with ozone. ${ }^{21}$

The two-phase oxidation has another advantage as it prevents the formation of ruthenium dioxide on to which the polysaccharide may be adsorbed, thereby preventing complete oxidation.

The presented degradation method permits the step-wise elimination of sugar residues in a methylated polysaccharide, thus providing a method which, in combination with methylation analysis, should be valuable for sequencing large structural entities. 


\section{EXPERIMENTAL}

General methods. Concentrations were performed under diminished pressure, at bath temperatures not exceeding $40^{\circ}$. For GLC, a Perkin-Elmer 900 instrument, fitted with flame-ionisation detectors, was used. Separations were performed on (a) glass-columns $(190 \times 0.15 \mathrm{~cm})$ containing $3 \%$ ECNSS-M on Gas Chrom Q $(100-120 \mathrm{mesh})$ at $170^{\circ}$, (b) OV-225 SCOT columns $(15 \mathrm{~m} \times 0.5 \mathrm{~mm})$ at $190^{\circ}$. For quantitative evaluations of the GLC, a Hewlett Packard $3370 \mathrm{~B}$ integrator was used. For GLC - MS a Perkin-Elmer 270 instrument and the same columns as above were used.

\section{Sequential degradation of the LPS from $S . t y p h i$ - $m u r i u m$ L $\mathrm{T} 2$}

Methylation. LPS $^{8}(60 \mathrm{mg})$ in dimethyl sulphoxide $(20 \mathrm{ml})$ was treated with $2 \mathrm{M}$ methylsulphinyl anion $(20 \mathrm{ml})$ under nitrogen. The resulting solution was agitated ultrasonically for $30 \mathrm{~min}$ and then kept for $4 \mathrm{~h}$ at room temperature. Methyl iodide $(10 \mathrm{ml})$ was then added dropwise with external cooling. The turbid solution was agitated ultrasonically for $30 \mathrm{~min}$, giving a clear solution. Methyl iodide was then distilled off and the solution was dialysed against running tap water overnight and then against distilled water overnight. The resulting suspension was freeze-dried giving methylated LPS (73 mg). A sample (3 mg) was hydrolysed, transformed into alditol acetates and analysed by GLC - MS ${ }^{12}$ ('Table 1, column A).

Partial acid hydrolysis. Methylated LPS $(70 \mathrm{mg})$ was treated with $50 \%$ aqueous acetic acid $(90 \mathrm{ml})$ for $14 \mathrm{~h}$ on a boiling water bath. The solution was evaporated to dryness and the product was fractionated on a Sephadex LH 20 column $(28 \times 3 \mathrm{~cm})$ using chloro. form-acetone $(3: 1)$ as irrigant. The separation was monitored polarimetrically. The modified polysaccharide $(30 \mathrm{mg})$ was eluted with the void volume. Part of the product was trideuteriomethylated and analysed as described earlier (Table 1, column B). The partially methylated alditol acetate with a trideuteriomethoxyl group gave a mass spectrum in which fragments containing this group were shifted by three mass units.

Oxidation. Methylated partially hydrolysed polysaccharide (10 $\mathrm{mg})$ in dichloromethane $(3 \mathrm{ml})$ was treated with $0.08 \mathrm{M}$ ruthenium tetraoxide in dichloromethane $(8 \mathrm{ml})$. After addition of a saturated aqueous solution of sodium metaperiodate the reaction mixture was shaken vigorously until the solution became yellow $(\simeq 15 \mathrm{~min})$. The aqueous layer was separated and the organic phase was washed with water $(4 \times 5 \mathrm{ml})$ and evaporated to dryness.

Alkaline degradation. The oxidised material from above was dissolved in dichloro. methane $(4 \mathrm{ml})$ and ethanolic $1 \mathrm{M}$ sodium ethoxide $(2 \mathrm{ml})$ was added. The reaction mixture was kept at room temperature for $30 \mathrm{~min}$ and then evaporated. The material was divided into two portions. One was hydrolysed and the sugars were analysed as before (Table 1, column C). The other portion was reetherified using trideuteriomethyl iodide, hydrolysed and analysed as before (Table 1, column D).

\section{Sequential degradation of the capsular poly- saccharide from Klebsiella ty pe 47}

Methylation and elimination of the uronosylic residue and isolation of the degraded polysaccharide was performed as earlier described ${ }^{2}$ (Table 2, column A and B).

Oxidation of a $10 \mathrm{mg}$ sample of methylated, degraded polysaccharide was performed as described above.

Alkaline degradation. The oxidised material was dissolved in dichloromethane $(4 \mathrm{ml})$ and ethanolic $1 \mathrm{M}$ sodium ethoxide $(2 \mathrm{ml})$ for $30 \mathrm{~min}$, neutralised with acetic acid and evaporated. The material was divided into two portions. One was hydrolysed and the sugars analysed as before (Table 2, column C). The other portion was reetherified using ethyl iodide, hydrolysed and analysed as before (Table 2, column D). The partially methylated and ethylated alditol acetate gave a mass spectrum in which fragments containing an ethoxy group were shifted fourteen mass units.

Acta Chem. Scand. 27 (1973) No. 10 
Acknowledgements. The skilled technical assistance of Mrs. Jana Cederstrand and Miss Birgitta Sundberg is acknowledged. The authors are indebted to Statens Naturvetenskapliga Forskningsraid for financial support, to Pharmacia AB for a fellowship to one of us (L.K.) and to Professor Bengt Lindberg for his interest.

\section{REFERENCES}

1. Lindberg, B. and Lundström, H. Acta Chem. Scand. 20 (1966) 2423.

2. Lindberg, B., Lönngren, J. and Thompson, J. L. Carbohyd. Res. 28 (1973) 351.

3. Aspinall, G. O. and Barron, P. E. Can. J. Chem. 50 (1972) 2203.

4. Beynon, P. J., Collins, P. M., Doganges, P. T. and Overend, W. G. J. Chem. Soc. C 19661131.

5. Kenne, L. and Svensson, S. Acta Chem. Scand. 26 (1972) 2144.

6. Kenne, L., Larm, O. and Svensson, S. Acta Chem. Scand. 26 (1972) 2473.

7. Kenne, L., Larm, O. and Svensson, S. Acta Chem. Scand. 27 (1973) 2797.

8. Hellerqvist, C. G., Lindberg, B., Svensson, S., Holme, T. and Lindberg, A. A. Carbohyd. Res. 9 (1969) 237.

9. Hellerqvist, C. G., Larm, O., Lindberg, B. and Lindberg, A. A. Acta Chem. Scand. 25 (1971) 744 .

10. Robbins, P. W. and Wright, A. Microbial toxins, Academic, New York 1971, Vol. 4, p. 351 .

11. Hakomori, S. J. Biochem. (Tokyo) 55 (1964) 205.

12. Björndal, H., Hellerqvist, C. G., Lindberg, B. and Svensson, S. Angew. Chem. Int. Ed. 9 (1970) 610.

13. Björndal, H., Lindberg, B., Lönngren, J. Rosell, K.-G. and Nimmich, W. Carbohyd. Res. 27 (1973) 373.

14. Troy, F. A., Frerman, F. E. and Heath, E. C. J. Biol. Chem. 246 (1971) 118.

15. Sutherland, I. W. and Wilkinson, J. F. Biochem. J. 110 (1968) 749.

16. Yurewicz, E. C., Ghalambor, M. A. and Heath, E. C. J. Biol. Chem. 246 (1971) 5596.

17. Anet, E. F. L. J. Chem. Ind. (London) 19631035.

18. Kenne, L., Rosell, K.-G. and Svensson, S. Unpublished results.

19. Hoffman, J., Kenne, L. and Svensson, S. Unpublished results.

20. Angyal, S. J. and James, K. Aust. J. Chem. 23 (1970) 1209.

21. Deslongchamps, P. and Moreau, C. Can. J. Chem. 49 (1971) 2465.

Received July 13, 1973. 